\title{
Suppression of CINNAMOYL-COA REDUCTASE increases the level of monolignol ferulates incorporated into maize lignins
}

\author{
Rebecca A. Smith ${ }^{1,2^{*}}$, Cynthia L. Cass ${ }^{3}$, Mona Mazaheri ${ }^{1,4}$, Rajandeep S. Sekhon 1,4,6, Marlies Heckwolf ${ }^{1,4}$, \\ Heidi Kaeppler ${ }^{1,4}$, Natalia de Leon ${ }^{1,4}$, Shawn D. Mansfield ${ }^{5}$, Shawn M. Kaeppler ${ }^{1,4}$, John C. Sedbrook ${ }^{3}$, \\ Steven D. Karlen ${ }^{1,2}$ and John Ralph ${ }^{1,2}$
}

\begin{abstract}
Background: The cell wall polymer lignin provides structural support and rigidity to plant cell walls, and therefore to the plant body. However, the recalcitrance associated with lignin impedes the extraction of polysaccharides from the cell wall to make plant-based biofuels and biomaterials. The cell wall digestibility can be improved by introducing labile ester bonds into the lignin backbone that can be easily broken under mild base treatment at room temperature. The FERULOYL-COA MONOLIGNOL TRANSFERASE (FMT) enzyme, which may be naturally found in many plants, uses feruloyl-CoA and monolignols to synthesize the ester-linked monolignol ferulate conjugates. A mutation in the first lignin-specific biosynthetic enzyme, CINNAMOYL-CoA REDUCTASE (CCR), results in an increase in the intracellular pool of feruloyl-CoA.

Results: Maize (Zea mays) has a native putative FMT enzyme, and its ccr mutants produce an increased pool of feruloyl-CoA that can be used for conversion to monolignol ferulate conjugates. The decreased lignin content and monomers did not, however, impact the plant growth or biomass. The increase in monolignol conjugates correlated with an improvement in the digestibility of maize stem rind tissue.
\end{abstract}

Conclusions: Together, increased monolignol ferulates and improved digestibility in ccr1 mutant plants suggests that they may be superior biofuel crops.

Keywords: Zea mays, Mass spectrometry, Cell wall digestibility, Biofuels

\section{Background}

One of the front contenders to replace the currently used petroleum fuel sources is cellulosic biofuels. Plant material, such as corn stover, is an excellent source of cell wall material, but the lignin in the wall makes it difficult to deconstruct and effectively recover the valuable polysaccharides for conversion to fuels and other coproducts. Lignin is a complex phenolic polymer built from a variety of phenolic monomers coupled together with an assortment of $\mathrm{C}-\mathrm{C}$ and $\mathrm{C}-\mathrm{O}-\mathrm{C}$ (ether) linkages. As a result,

\footnotetext{
*Correspondence: rasmith29@wisc.edu

${ }^{1}$ Department of Energy Great Lakes Bioenergy Research Center, The Wisconsin Energy Institute, University of Wisconsin-Madison, 1552 University Avenue, Madison, WI 53726-4084, USA

Full list of author information is available at the end of the article
}

the absolute structure of lignin is not defined, and the polymer cannot be easily degraded because of the difficulty in cleaving its $\mathrm{C}-\mathrm{C}$ and even its ether bonds. Studies are therefore underway to reduce the recalcitrance of lignin without negatively impacting the growth and development of the plant.

Recent success in this field was achieved by introducing an exotic FERULOYL-CoA MONOLIGNOL TRANSFERASE (FMT) gene from Angelica sinensis into poplar (Populus alba $\times$ grandidentata) [1] resulting in trees that produce an FMT enzyme responsible for synthesizing monolignol ferulate conjugates. Monolignol ferulates (ML-FAs) are derived from FMT-catalyzed acylation of lignin monomeric units, monolignols (ML), at the $\gamma$-hydroxy position by ferulate (FA), via feruloyl-CoA, 
an intermediate in the lignin biosynthetic pathway. The result was poplar trees with higher levels of ML-FAs incorporated into the lignin. Unlike the least recalcitrant of the interunit linkages in the lignin polymer, the $\beta$-ethers that require $\sim 130{ }^{\circ} \mathrm{C}$ to cleave at a moderate rate of $10^{-3} / \mathrm{min}$ in $1 \mathrm{M} \mathrm{NaOH}$ [2], the esters in these modified lignins were easily broken by base treatment even at room temperature, improving the saccharification of the wood [1]. As the trees did not experience any significant growth defects, this study suggested that the monolignol ferulate strategy had enormous potential for the development of plants for biofuel and biomaterials applications.

Recent improvements in the detection sensitivity for releasable diagnostic ML-FA-derived components have led to the discovery that wild-type poplar also naturally produces ML-FAs, albeit at a lower level, and incorporates them into the lignin polymer. Therefore, poplar must have a native FMT enzyme, or a multi-functional enzyme with FMT capabilities. Other major bioenergy crops have also been shown to have natural levels of MLFAs incorporated into their lignins [3]. These include many economically important monocot and eudicot plant species, such as maize, switchgrass, sorghum, miscanthus, and eucalyptus.

Given that ML-FAs, and therefore presumably FMT enzymes, are naturally occurring, we hypothesized that the levels of ML-FAs could be manipulated by perturbing the relative levels of the substrate pool available to the FMT enzyme. Higher levels of ML-FAs could prove valuable, as there is a correlation between the levels of MLFAs and the digestibility of the cell wall following alkaline pretreatments $[1,4]$. Previous studies of the lignin biosynthetic pathway have shown that downregulating the CINNAMOYL-CoA REDUCTASE (CCR1) gene, which encodes an enzyme with the main function of converting feruloyl-CoA into coniferaldehyde, results in a pool of feruloyl-CoA (FA-CoA) and its derivatives [5-7]. The levels of ML-FAs in lignin biosynthetic mutants, such as ccr1 mutants, have not previously been investigated. Increasing the pool of the FA-CoA intermediate could therefore provide more substrate for the naturally occurring FMT enzyme and increase the amount of ML-FAs, which could in turn improve the digestibility of the cell walls, as outlined in Fig. 1.

To test this hypothesis, we examined the levels of MLFAs releasable from a maize $c c r 1$ mutant line. Maize is a biofuel crop of interest as well as a valuable model monocot system. As we illustrate, maize ccr1 mutant plants, hypothesized to have an increased pool of the feruloyl-CoA substrate, displayed markedly higher levels of lignin-incorporated ML-FAs, along with lower total lignin, and improved biomass digestibility, without detriment to overall plant growth.

\section{Results and discussion}

To examine the levels of ML-FAs incorporated into ccr1 mutants, we used established genetically uniform W22 maize inbred lines obtained from the UniformMu collection [8]. The line analyzed in this study harbors a $\mathrm{Mu}$ transposon in exon four of the CCR1 gene (GRMZM2G131205, Additional file 1: Fig. 1A, B); for further details, see Materials and Methods. Mutant $c c r 1$ maize plants (Zmccr1) and wild-type W22 controls were grown in both the greenhouse and the field, and stem tissue from all plants were sampled at maturity. Reversetranscription semi-quantitative PCR determined that plants homozygous for the mu1013391 insertion had reduced $c c r 1$ transcript present compared to wild type (Additional file 1: Fig. 1C). A complete knock-out of the CCR1 gene has been reported to cause severe growth defects and drastic decreases in total lignin content in various monocots and eudicots $[5,7,9,10]$. Despite the reduced $c c r 1$ transcript level, the maize plants here appear no different from wild type in their growth and biomass yields when grown in a greenhouse (Fig. 2a). This has previously been reported for other $c c r$ mutants in maize, which had normal seed germination, growth, and development [11].

The total lignin level and lignin monomer content were analyzed for each line by Klason lignin analysis and thioacidolysis, respectively. The acid-insoluble lignin content was significantly decreased in the $c c r 1$ plants relative to wild type (17.7 versus $22 \%$; Table 1 ). Surprisingly, this lignin decrease did not negatively impact the growth of the mutant plants. Correlated with the lower lignin level, the total amount of released guaiacyl (G) and syringyl (S) thioacidolysis monomers was also lower, as has been previously reported $[7,9]$. Thioacidolysis releases monomers by selectively cleaving $\beta-\mathrm{O}-4$-linkages between monomeric units; the monomer yields therefore represent only a fraction of the units $(\sim 30 \%)$, but reflect the approximate proportion of each monolignol incorporated into the lignin polymer (see Table 2 for calculation of theoretical yields). As anticipated for a mutation in the first lignin-specific enzyme in the phenylpropanoid pathway, the $c c r 1$ mutation reduces all monolignol biosynthesis. The major difference was observed in G monomers (30-71 micromoles per $\mathrm{g}$ AIR in mutants versus 100-133 in WT), as has been noted previously when the flux into the monolignol pathway is reduced (Fig. 2; Table 1); the $p$-hydroxyphenyl $(\mathrm{H})$ and $\mathrm{S}$ monomers were also lower in the mutant (approximately 40 and 30\% decrease, respectively).

The levels of monolignol conjugates in the lignin polymer, and not just monolignol levels, were of particular interest in the $c c r 1$ mutant plants because of our hypothesis that the increased pool of feruloyl-CoA generated by 

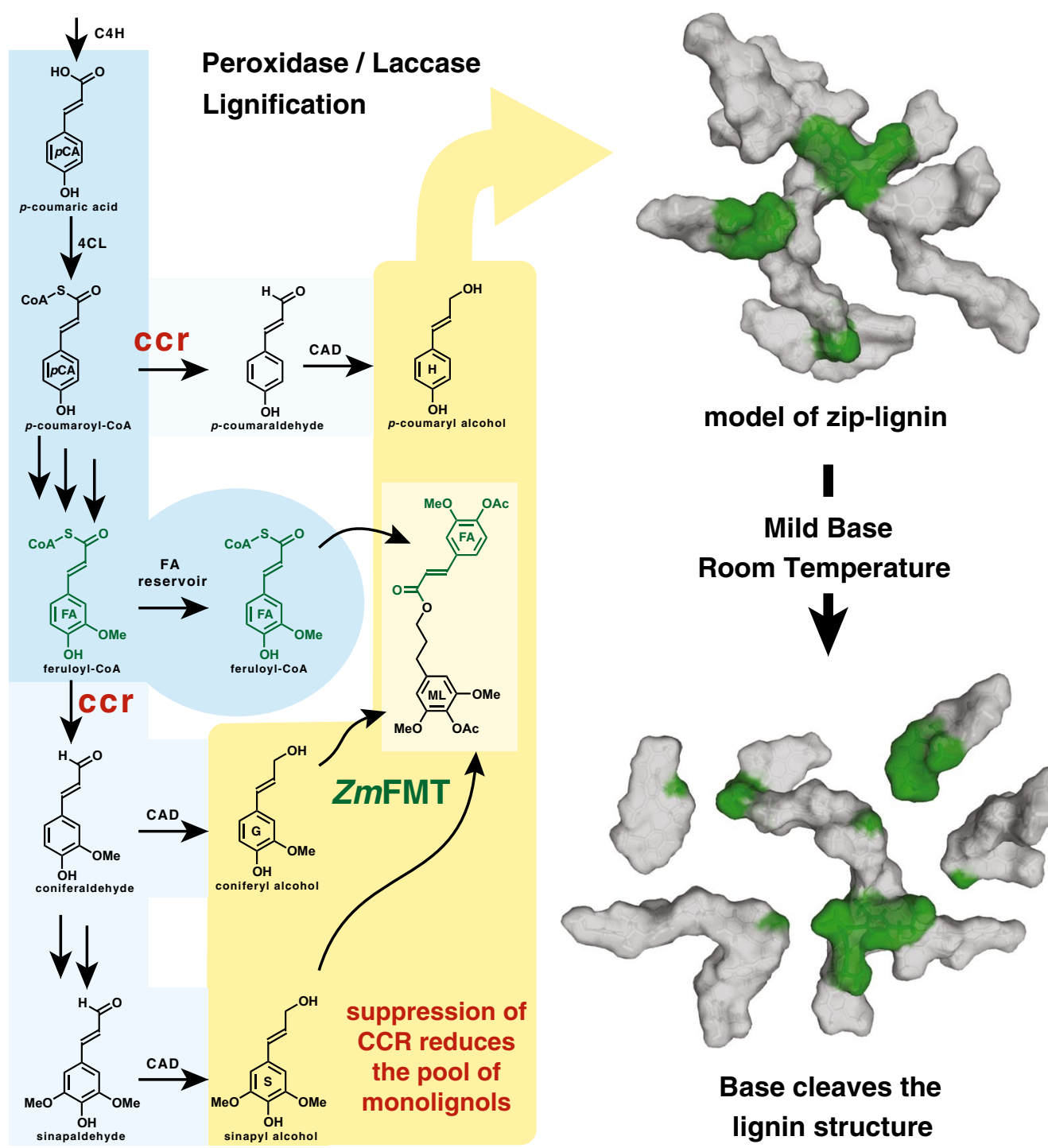

model of zip-lignin

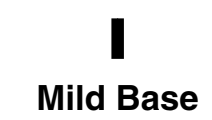

Room Temperature

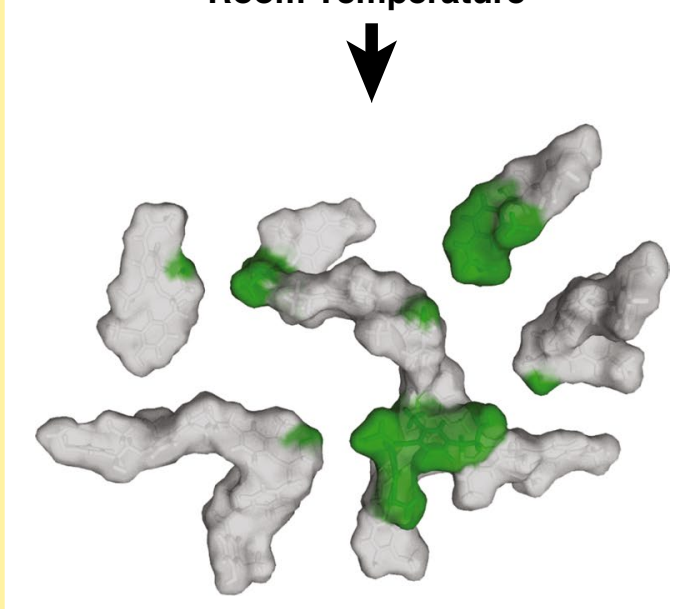

Base cleaves the
lignin structure

Fig. 1 An abbreviated version of the lignin biosynthetic pathway highlighting the effects of the $c c r 1$ mutation. The mutated CCR 1 gene results in reduced CCR1 transcript, and presumably less CCR1 enzyme, and a pool of feruloyl-CoA (FA reservoir). The conjugates formed between the monolignols and feruloyl-COA by ZmFMT are incorporated into the lignin polymer, generating a zip-lignin in which the ester bonds in the backbone are readily cleaved by base

reduced CCR1 activity could lead to increased production of ML-FAs. Derivatization Followed by Reductive Cleavage (DFRC), a method that cleaves $\beta$-ethers but leaves $\gamma$-esters intact, was the first method to effectively examine and relatively quantify the incorporation of ML-FAs into the lignin polymer [1]. The method liberates diagnostic ester conjugates but, due to the complex and combinatorial manner that ML-FAs incorporate into lignins (see Fig. S2 in [1]), only a small fraction is released and quantifiable. DFRC analysis of maize wildtype (W22 background) and ccr1 mutant plants revealed a three- to fivefold higher level of ML-FAs released from $c c r 1$ relative to wild-type plants (300 versus 800 $1200 \mathrm{nmol}$ ML-FA per gram lignin). The elevated level was the result of higher quantities of both coniferyl and sinapyl ferulates, but sinapyl ferulates are much more prominent (Fig. 3, Additional file 1: Fig. 2), as is typical for most monocot species [3]. This result indicates that the pool of feruloyl-CoA generated by the $c c r 1$ mutation is used by the putative natural maize $Z m F M T$ to generate more monolignol conjugates that are then used for lignification.

In addition to monolignol ferulate conjugates, maize also naturally produces another class of conjugates, the 


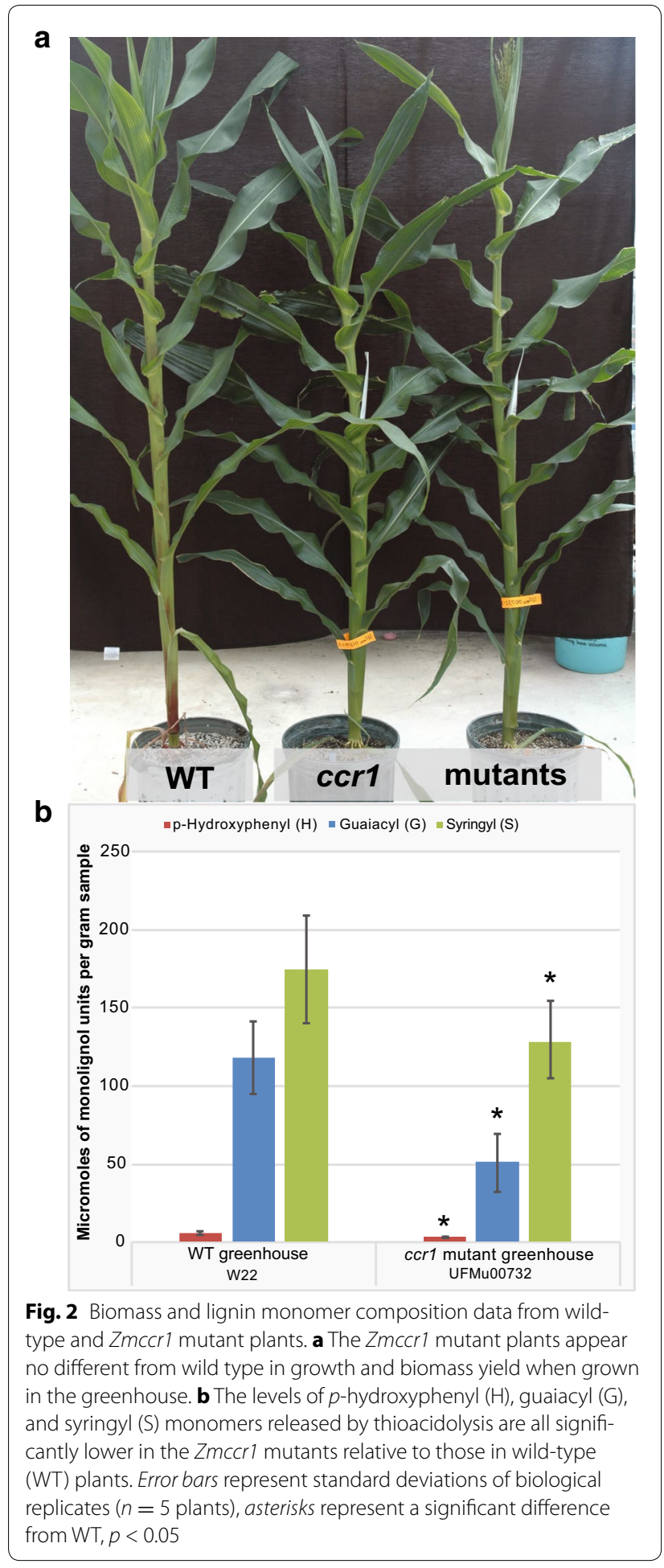

monolignol $p$-coumarates (ML- $p \mathrm{CA})$ via the $p$-COUMAROYL-CoA MONOLIGNOL TRANSFERASE (ZmPMT, also referred to as $p$ CAT) enzyme [12]. PMT synthesizes ML- $p$ CAs by the conjugation of monolignols to $p$-coumaroyl-CoA $[13,14]$. The levels of ML- $p$ CAs were not significantly altered in the $c c r 1$ mutant plants that had the higher ML-FA quantities relative to wildtype plants (Fig. 3). This indicates that the production of ML-FAs and ML- $p$ CAs are independent, and are most likely synthesized via separate enzymes, i.e., the putative $Z m F M T s$ and $Z m P M T s$, respectively.

As a negative control to ensure that the increased pool of feruloyl-CoA was correlated with the increased monolignol ferulate levels (i.e., that natural FMTs are using (some of) the excess feruloyl-CoA to generate ML-FAs), Arabidopsis thaliana ccr1 knock-out mutants were examined for the presence of ML-FAs. Arabidopsis does not have an FMT enzyme, as discerned from the absence of ML-FAs, or indeed any of the monolignol conjugates, in the wild-type plants [3]. The Arabidopsis ccr1 mutants did not produce any detectable level of ML-FAs (Additional file 1: Fig. 2), but did generate a pool of ferulate derivatives [5], supporting the idea that the increase in ML-FAs in the maize mutants is the result of FMT activity (that is absent in Arabidopsis).

In FMT-poplar trees, the increased production of MLFAs was correlated with increased cell wall digestibility following mild base pretreatment [1]. We subjected the maize ccr1 mutant plants, with their higher levels of MLFAs, to partial saccharification analysis, following mild base $\left(6.25 \mathrm{mM} \mathrm{NaOH}, 90{ }^{\circ} \mathrm{C}\right.$ for $\left.3 \mathrm{~h}\right)$ pretreatment. The digestibility of the $c c r 1$ senesced tissues, as measured by glucose release, was significantly higher than that of wild-type plants ( 15 to 20 versus $10 \%$, respectively; Fig. 4; Table 1). This improvement may be due, in part, to the decreased total lignin level in the plants but, with the precedent set by Wilkerson et al. [1] of the correlation between ML-FA levels and improved digestibility in plants without changes in total lignin, is also likely related to the increased levels of ML-FAs incorporated into the lignin. Park et al. [11] reported improved digestibility of $R N A i-C C R 1$ maize plants when pretreated by ammonia fiber expansion (AFEX).

Taken together, the growth and chemical analysis data all suggest that greenhouse-grown ccrl mutants have excellent potential for biofuels production. Greenhouse conditions, however, are optimal for plant growth and are not necessarily representative of how the plants perform in the field. Field trials of $c c r 1$ mutants demonstrated that the $c c r 1$ mutation does not confer any deleterious effect on agronomic performance and, in fact, the ccr1 mutant plants produced significantly more biomass than wild-type control maize plants (Table 3). The Klason acid-insoluble lignin levels matched those of the greenhouse-grown wild-type and ccr 1 mutant plants (Table 1). 
Table 1 Chemical analysis values for wild-type (WT) and ccr1 mutant plants

\begin{tabular}{|c|c|c|c|c|}
\hline & $\begin{array}{l}\text { UFMu00732 ccr1 } \\
\text { mutants (greenhouse) }\end{array}$ & $\begin{array}{l}\text { WT W22 maize } \\
\text { plants (greenhouse) }\end{array}$ & $\begin{array}{l}\text { UFMu00732 ccr1 } \\
\text { mutants (field-grown) }\end{array}$ & $\begin{array}{l}\text { WT W22 maize } \\
\text { plants (field-grown) }\end{array}$ \\
\hline \% Acid-insoluble Klason lignin & $17.7 \% \pm 0.8$ & $22.0 \% \pm 0.1$ & $17.3 \% \pm 0.2$ & $22.8 \% \pm 0.2$ \\
\hline \multicolumn{5}{|l|}{ Thioacidolysis } \\
\hline S:G:H ratios & $71: 27: 1.6$ & $59: 40: 1.7$ & $68: 28: 4$ & $60: 37: 3$ \\
\hline $\mathrm{H}(\mu \mathrm{mol} / \mathrm{g})$ & $2.9 \pm 0.4$ & $4.9 \pm 1.1$ & $2.8 \pm 0.1$ & $4.2 \pm 0.2$ \\
\hline $\mathrm{G}(\mu \mathrm{mol} / \mathrm{g})$ & $50.6 \pm 18.4$ & $117.1 \pm 23.0$ & $18.9 \pm 1.3$ & $48.1 \pm 0.74$ \\
\hline $\mathrm{S}(\mu \mathrm{mol} / \mathrm{g})$ & $127.8 \pm 25$ & $173.9 \pm 34.2$ & $45.5 \pm 2.3$ & $78.1 \pm 2.0$ \\
\hline \multicolumn{5}{|l|}{ DFRC } \\
\hline CA-DHFA nmol/g lignin & $96.4 \pm 30.7$ & $107.6 \pm 31.0$ & $95.9 \pm 8.2$ & $123.4 \pm 19.3$ \\
\hline SA-DHFA nmol/g lignin & $911.7 \pm 141.1$ & $308.9 \pm 3.2$ & $1775.7 \pm 39.0$ & $1039.4 \pm 139.9$ \\
\hline CA-DHpCA nmol/g lignin & $12,554.9 \pm 2453.6$ & $9551.8 \pm 1220.8$ & $13,739.8 \pm 18.0$ & $12,730.1 \pm 621.5$ \\
\hline SA-DHpCA nmol/g lignin & $319,314.6 \pm 33,334.7$ & $275,157.7 \pm 850.4$ & $238,058.8 \pm 4112.7$ & $292,782.2 \pm 20,356.2$ \\
\hline \multicolumn{5}{|l|}{ Digestibility } \\
\hline$\%$ Glucose & $17.9 \% \pm 1.8$ & $11.7 \% \pm 1.4$ & $16.0 \% \pm 0.1$ & $11.4 \% \pm 0.3$ \\
\hline$\%$ Pentose & $6.4 \% \pm 0.7$ & $4.3 \% \pm 0.6$ & $4.9 \% \pm 0.2$ & $4.2 \% \pm 0.3$ \\
\hline
\end{tabular}

Table 2 Calculation of the percentage of lignin quantified by DFRC and thioacidolysis

\begin{tabular}{|c|c|c|}
\hline Chemical assay & DFRC & Thioacidolysis \\
\hline Whole cell-wall sample & $50 \mathrm{mg}$ & $50 \mathrm{mg}$ \\
\hline Klason lignin (wt\%) & $22 \%$ & $22 \%$ \\
\hline $\begin{array}{l}\text { Approximate mass of lignin (wt\% Klason } \\
\text { lignin } \times 50 \text { mg wcw) }\end{array}$ & $11,000 \mu \mathrm{g}$ & $11,000 \mu \mathrm{g}$ \\
\hline $\begin{array}{l}\text { Mass of products quantified ( } \mu \mathrm{mol} / \mathrm{mg} \\
\mathrm{wCw} \times \mu \mathrm{g} / \mu \mathrm{mol})\end{array}$ & $2300 \mu \mathrm{g}$ & $2900 \mu \mathrm{g}$ \\
\hline Weight $\%$ of lignin detected & $21 \%$ & $26 \%$ \\
\hline
\end{tabular}

Component compositional analysis of lignin by degradative assays,

thioacidolysis, and DFRC, only accounts for a portion of the total lignin structure.

A calculation approximating the amount of lignin that each of these assays measures can be performed by comparing the weight of the components that are quantified and the amount of Klason lignin in the sample. In this study, wildtype maize rind tissue was $\sim 22 \% \mathrm{Klason}$ lignin. The detected product was then converted to the weight of the lignin components, i.e., the $\mathrm{H}, \mathrm{G}, \mathrm{S}, \mathrm{ML}-\mathrm{DH} p \mathrm{CA}$, and ML-DHFA structures are converted into the non-functionalized monolignols and hydroxycinnamic acids. Taking the summation of the weight of these components and dividing mass of lignin gave an approximate weight $\%$ of the lignin that was detected. The products of the DFRC analysis of wild-type maize rind tissue in this study accounted for $\sim 21 \%$ of the total lignin, whereas the product mix from thioacidolysis accounted for $\sim 26 \%$ of the lignin

The field-grown wild-type stems had levels of ML-FAs similar to those of greenhouse-grown $c c r 1$ mutants, whereas the field-grown $c c r$ plants had an almost twofold higher ML-FA release than greenhouse-grown $c c r 1$ mutants (Fig. 3a). The changes in ML-FA levels did not impact the ML- $p C A$ release levels determined, as these levels were similar between all greenhouse-grown and field-grown plants (Fig. 3b). These data all align with the contention that $c c r 1$ mutants, with higher ML-FA levels and improved digestibility, are viable biofuel crops.

\section{Conclusions}

Increasing the biosynthesis of monolignol ferulates, and thereby increasing the digestibility of the cell wall, appears to be regulated by at least one key factor. In maize, the amount of feruloyl-CoA substrate appears to be a limiting factor in the production of monolignol ferulates by a putative ZmFMT. The increased monolignol ferulate incorporation into lignins in $c c r 1$ mutant plants suggests that they may provide superior biofuels substrates, and even higher stover yields, and could have implications for viable methods by which to increase monolignol ferulate levels in other biofuel crops, such as trees or sorghum.

\section{Methods}

\section{Plant growth conditions and field evaluation}

$\mathrm{F}_{3}$ generation CCR1 mutant UniformMu seed stocks UFMu-00732 (Zmccr 1a) and UFMu01379 (Zmccr 1b) harboring the $\mathrm{Mu}$ transposon mu1013391 in exon four of the CCR1 gene (GRMZM2G131205, Chr1: 211567137.0.211573211, http://www.maizegdb.org) (Additional file 1: Fig. 1A) were obtained from the Maize Genetics Cooperation Stock Center (http://www.maizegdb. org/ordering/stock). Mutant plants grown from $\mathrm{F}_{3}$ seeds were identified by a PCR assay and were self-pollinated. Homozygous CCR1 mutant progenies and wild type (W22 inbreds) were planted in a greenhouse $\left(27^{\circ} \mathrm{C}\right.$ day, $24{ }^{\circ} \mathrm{C}$ night, $16 \mathrm{~h}$ day (light), $8 \mathrm{~h}$ dark).

Arabidopsis thaliana cinnamoyl-CoA reductase1 ( $c c r 1^{\text {irxy }}$; AT1G15950) mutants were obtained from the Arabidopsis Biological Resource Center (ABRC) and were grown to senescence in a growth chamber $\left(21{ }^{\circ} \mathrm{C}\right.$ day, $16 \mathrm{~h}$ day (light), $8 \mathrm{~h}$ dark). 


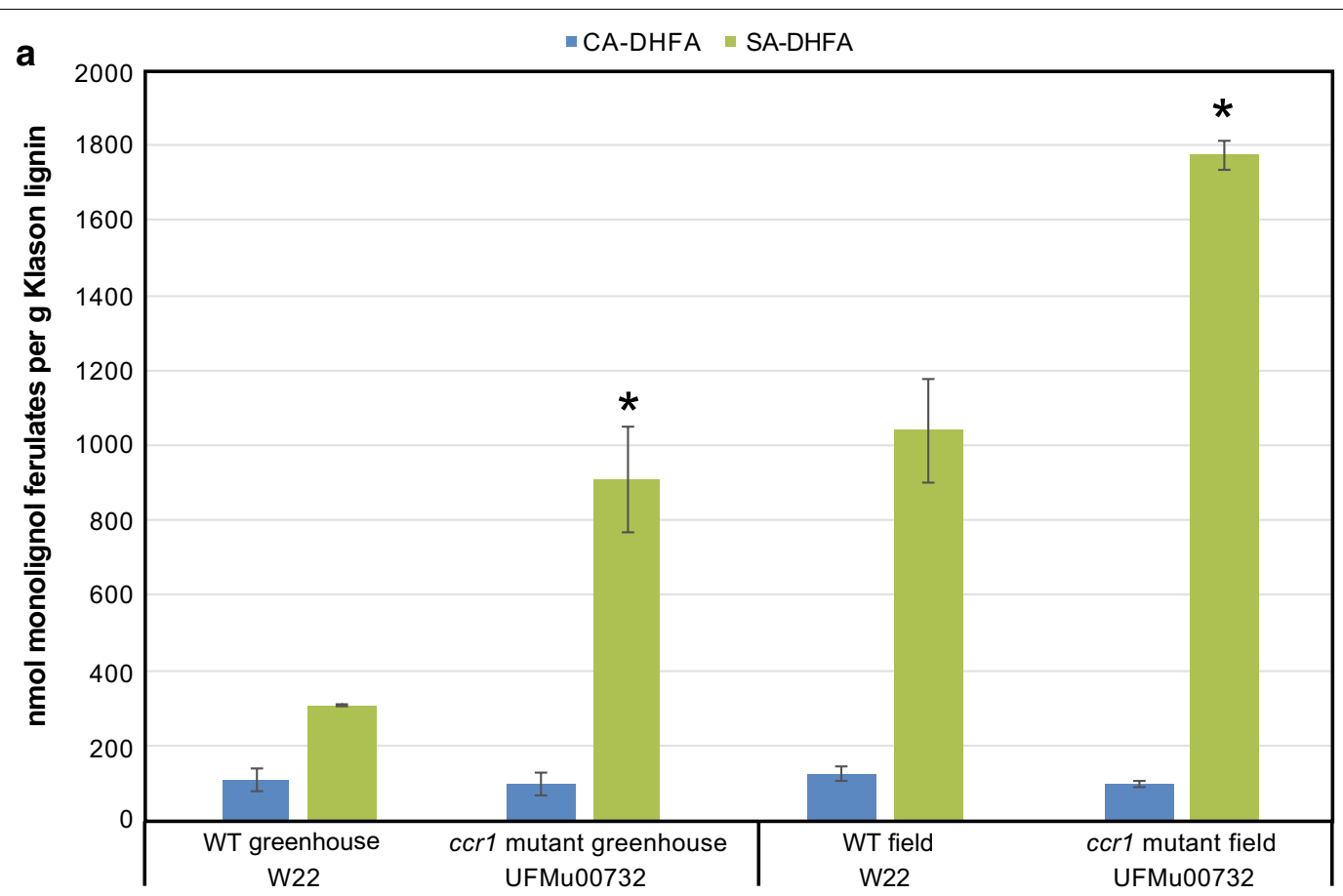

b

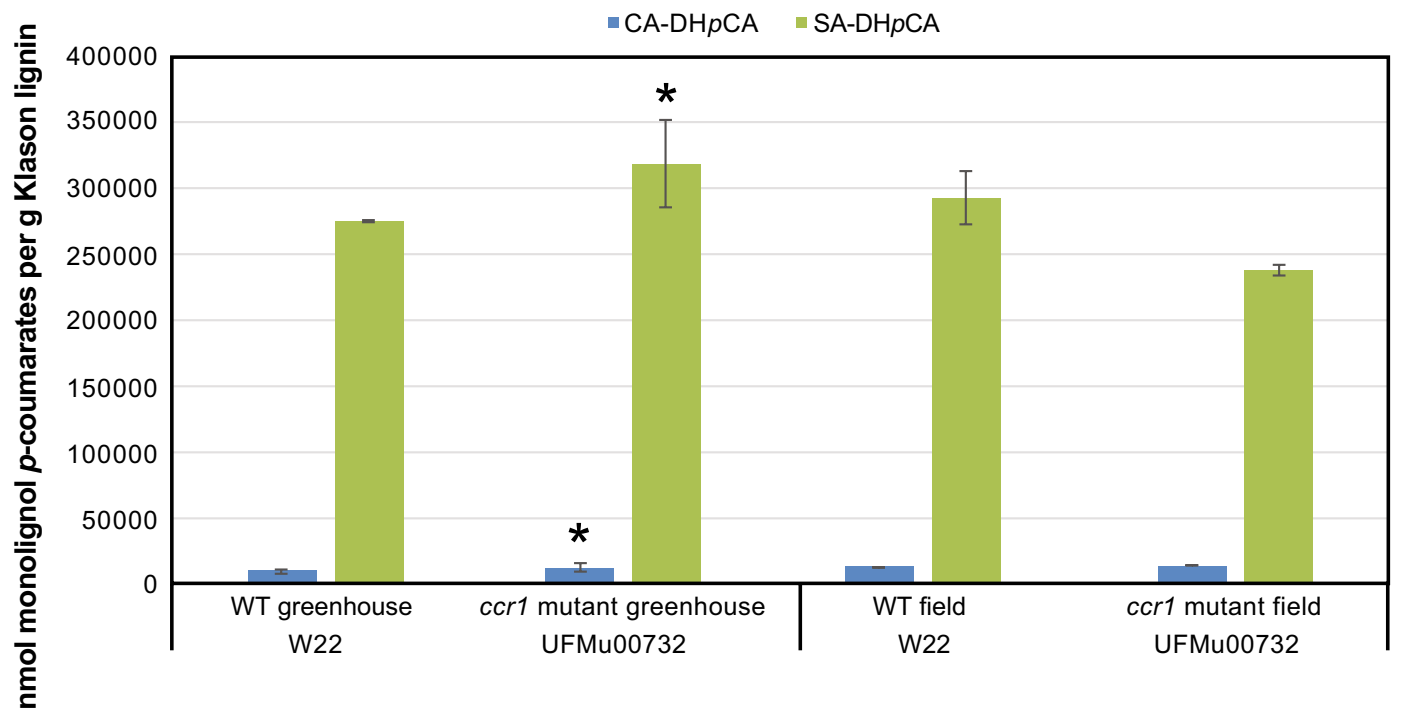

Fig. 3 The levels of monolignol conjugates released from DFRC analysis. a The level of monolignol dihydroferulate (ML-DHFA) conjugates released from Zmccrl mutants is three to fivefold higher than from wild-type (WT) plants, indicating higher ML-DHFA production and incorporation into the lignin polymer. b The level of monolignol dihydro-p-coumarates (ML-DHpCA) is similar between the Zmccr1 mutants and the wild-type plants, indicating that the production of monolignol ferulates and $p$-coumarates are independent. CA-FA/pCA is the coniferyl alcohol conjugate, SA-FA/pCA the sinapyl alcohol conjugate. Error bars represent standard deviation of biological replicates $(n=5$ plants for greenhouse lines, $n=2$ pools of 10 plants for field-grown lines), asterisks represent a significant difference from WT, $p<0.05$

For maize digestibility assays and the measurement of lignin, monomer composition (by thioacidolysis), and monolignol conjugates (by DFRC), the third internode below the topmost ear-bearing node was harvested at physiological maturity (40 days after anthesis).
Agronomic traits were measured on one-row plots in a randomized complete block design with six replications at the West Madison Research Station in Wisconsin from May to September, 2016. Plant height and ear height were measured from soil surface to the flag leaf node and 


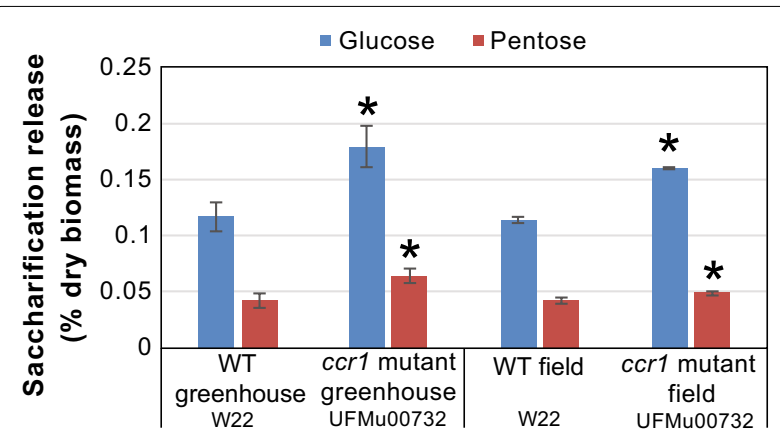

Fig. 4 Relative glucose and pentose release from limited-extent digestibility of Zmccr1 mutant lines is higher than from wild-type (WT) plants, both in greenhouse and field-grown maize. Error bars represent standard deviations of biological replicates ( $n=5$ plants for greenhouse lines, $n=2$ pools of 10 plants for field-grown lines), asterisks represent significant difference from WT, $p<0.05$

Table 3 Agronomic trait analysis of field-grown Zmccr1 mutants

\begin{tabular}{|c|c|c|c|}
\hline Trait & W22 & $\operatorname{ccr} 1(00732)$ & Significance \\
\hline Plant height (cm) & $173.7 \pm 9.6^{\mathrm{a}}$ & $187.2 \pm 10.3$ & * \\
\hline Ear height (cm) & $79.8 \pm 9.0$ & $87.1 \pm 8.4$ & * \\
\hline $\begin{array}{l}\text { Above-ear height } \\
(\mathrm{cm})\end{array}$ & $93.9 \pm 7.7$ & $100.1 \pm 7.5$ & * \\
\hline Node number & $15 \pm 0.5$ & $16 \pm 0.8$ & * \\
\hline $\begin{array}{l}\text { Below-ear node } \\
\text { number }\end{array}$ & $8 \pm 0.6$ & $8 \pm 0.6$ & ns \\
\hline $\begin{array}{l}\text { Above-ear node } \\
\text { number }\end{array}$ & $7 \pm 0.5$ & $7 \pm 0.6$ & $*$ \\
\hline $\begin{array}{l}\text { Internode length } \\
(\mathrm{cm})\end{array}$ & $11.4 \pm 0.7$ & $11.9 \pm 0.6$ & * \\
\hline $\begin{array}{l}\text { Above-ear inter- } \\
\text { node length }(\mathrm{cm})\end{array}$ & $13.4 \pm 0.5$ & $13.6 \pm 0.8$ & ns \\
\hline $\begin{array}{l}\text { Below-ear inter- } \\
\text { node length }(\mathrm{cm})\end{array}$ & $9.7 \pm 1.0$ & $10.3 \pm 0.7$ & * \\
\hline Days to flower & $71.3 \pm 0.5$ & $76.3 \pm 1.5$ & * \\
\hline Leaf length (cm) & $44.9 \pm 4.6$ & $49.8 \pm 3.8$ & * \\
\hline Leaf width (cm) & $9.5 \pm 0.6$ & $9.6 \pm 0.8$ & ns \\
\hline Stalk diameter (cm) & $3.1 \pm 0.2$ & $3.1 \pm 0.2$ & ns \\
\hline Stover weight (gr) & $73.7 \pm 3.7$ & $94.7 \pm 9.1$ & * \\
\hline Lodging (\%) & $3.106 \pm 3.752$ & $11.998 \pm 13.672$ & ns \\
\hline Seed weight (gr) & $60.482 \pm 8.006$ & $50.328 \pm 9.601$ & * \\
\hline
\end{tabular}

nsNon-significant

* Significance level of 0.05 ( $t$ test)

a Standard deviation

to the top ear node, respectively. The average internode length was estimated by dividing height by node number. Days to flower were recorded when more than half of the plants within a plot shed pollen. The second top leaf was used for taking leaf measurements. Leaf length was measured from the tip of the leaf to the leaf blade, and leaf width was measured from the leaf mid-region. Stalk diameter was calculated based on the circumference of the second above-ground internode. Lodge percentage was estimated based on the portion of lodged plants within each plot. Ears and stover were collected two months after the flowering date and were kept in a drier at $55{ }^{\circ} \mathrm{C}$ for a week after which seed and stover weight were measured.

\section{PCR and gene expression}

Genotyping for the Uniform Mu insertion mu1013391 found in seed stocks UFMu00732 and UFMu01379 in Zmccr1 (GRMZM2G131205, Chr1: 211567137.0.211573211, http://www.maizegdb.org) was performed using primers indicative of either the Uniform $\mathrm{Mu}$ insertion (T1 forward 5'-AACGCCTCCATTTCGTCGAATCC-3', R1 reverse 5'-GGTACTCGGGGAAGAGCTTGGC-3', 375-bp PCR product) or the wild-type CCR1 allele (F1 forward 5'-TACGACTTTGGTGGGTCGCTCG-3' ${ }^{\prime}$ and the R1 reverse primer, 537-bp PCR product). Amplification conditions for the T1-R1 primer pair were as follows: $94{ }^{\circ} \mathrm{C}-3 \mathrm{~min}$, one cycle; dissociation $94{ }^{\circ} \mathrm{C}-30 \mathrm{~s}$, annealing $60{ }^{\circ} \mathrm{C}-30 \mathrm{~s}$, extension $72{ }^{\circ} \mathrm{C}-20 \mathrm{~s}, 36$ cycles total; $72{ }^{\circ} \mathrm{C}-10 \mathrm{~min}$, one cycle; $4{ }^{\circ} \mathrm{C}$-hold; conditions for the $\mathrm{F} 1-\mathrm{R} 1$ primer pair were similar except that the annealing temperature was $59^{\circ} \mathrm{C}$ and the extension time was $30 \mathrm{~s}$ (Additional file 1: Fig. 1A, B). Sequenced PCR products confirmed that the mu1013391 was inserted into the GRMZM2G131205 locus, as reported by flanking sequence GenBank HQ140720.

For expression analysis, $500 \mathrm{ng}$ of leaf total RNA was reverse-transcribed by MMLV RT (Promega) using oligo $(\mathrm{dT})_{18}$ following the manufacturer's instructions. Zmccr1 expression level was determined by semi-quantitative PCR (real time-sqPCR) using $100 \mathrm{ng}$ of leaf first-strand cDNA in a $20-\mu \mathrm{L}$ reaction volume, and F2 forward $5^{\prime}$ TCCTCGCCAAGCTCTTCCCCGA- $3^{\prime}$ and R2 reverse 5'-AAGAACGAACATGACGTTACAAGTCTTAGG-3' primers that produced a 408-bp PCR product (Additional file 1: Fig. 1A, C). To ensure equal loading, Zea mays GAPDH (GRMZM2G180625) was used as a reference gene (forward 5'-GACCTCACTGTCAGAATCGAGA AGG-3' and reverse 5'-CACTCGTTGTCGTACCAAG AGACG-3' primers, 224-bp PCR product). Amplification conditions were $96{ }^{\circ} \mathrm{C}-3 \mathrm{~min}$, one cycle; $96^{\circ} \mathrm{C}-30 \mathrm{~s}$, $55^{\circ} \mathrm{C}-30 \mathrm{~s}, 72{ }^{\circ} \mathrm{C}-30 \mathrm{~s}, 28$ cycles total; $72{ }^{\circ} \mathrm{C}-10 \mathrm{~min}$, one cycle; $4{ }^{\circ} \mathrm{C}$-hold. The PCR products were verified by sequencing.

\section{Chemical analysis \\ Maize tissue sample}

All chemical assays were performed on the same homogenized maize rind tissue. The third internode below the topmost ear-bearing node was harvested from maize plants 
(WT; ccr1 mutant) at physiological maturity (40 days after anthesis) and dried in an oven at $42{ }^{\circ} \mathrm{C}$ for a week. The rind was isolated and ground to a fine powder using a Retsch mill at $301 / \mathrm{s}$ frequency for 2-3 min. Stem tissues were solvent extracted [water $(3 \times 40 \mathrm{~mL}), 80 \%$ ethanol $(3 \times 40 \mathrm{~mL})$ and acetone $(1 \times 40 \mathrm{~mL})]$ and freeze-dried for 2 days. The resulting powder was then homogenized and distributed for analysis.

Mature stem material from Arabidopsis ccr1 $1^{\text {irx4 }}$ mutants (pool of 10 plants) was isolated, ground, and solvent extracted, as described above.

\section{Klason lignin analysis}

Acid-insoluble lignin was determined using Klason lignin analysis of $150-200 \mathrm{mg}$ extractive-free rind tissue, as previously described [15]. Acid-soluble lignin was determined by measuring the absorbance at $205 \mathrm{~nm}$ of the filtrate after isolation of acid-insoluble lignin and calculated using an extinction coefficient of $110 \mathrm{~L} / \mathrm{g} \mathrm{cm}$.

\section{Thioacidolysis}

Thioacidolysis was performed at the Michigan State University's Cell Wall Facility to determine lignin composition following the original procedure [16, 17]. Briefly, the thioacidolysis reagent $(2.5 \%(\mathrm{v} / \mathrm{v})$ boron trifluoride diethyletherate, $10 \%(\mathrm{v} / \mathrm{v})$ ethanethiol in fresh dioxane) was spiked with $4,4^{\prime}$-ethylidenebisphenol $(1 \mathrm{mg} / \mathrm{mL}$ in dioxane) as an internal standard. Thioacidolysis monomers were extracted after $4 \mathrm{~h}$ at $100{ }^{\circ} \mathrm{C}$, then silylated with $\mathrm{N}, \mathrm{O}$-bis(trimethylsilyl)trifluoroacetamide and pyridine, and quantified by GC/MS (Agilent GC/MS, 6890 GC and 5975B MS) fitted with a Supelco SLB-5MS column $(30 \mathrm{~mm} \times 0.25 \mathrm{~mm} \times 0.25 \mu \mathrm{m}$ film) using synthetic thioacidolysis monomers as standards. The linear range and response factor (RF) for the synthetic monomers versus the internal standard (bisphenol E, ion 343) were as follows: for $\mathrm{S}, 25-300 \mu \mathrm{g}, r^{2}=0.998$, $\mathrm{RF}$ (ion 299) $=2.16$; for $\mathrm{G}, 25-300 \mu \mathrm{g}, r^{2}=0.998$, RF (ion 269) $=2.15$; and for $\mathrm{H}, 2.5-50 \mu \mathrm{g}, r^{2}=0.998$, RF (ion 239) $=2.11$. Each line represents an average of five biological replicates composed of two technical replicates each. The error bars in the graphical results represent the standard deviation between the biological replicates. Statistical analysis was performed by paired $t$ tests between $c c r 1$ mutants and corresponding wild-type plants with a significance level of 0.05 .

\section{Derivatization followed by reductive cleavage (DFRC) method for lignin-bound ML-FAs}

The quantitation of lignin-bound $M L-F A s$ was performed using the DFRC method that cleaves lignin $\beta$-ethers while retaining esters $[13,18-21]$, as recently described [3]. The same dry extract-free whole cell walls used for Klason lignin analysis $(50 \mathrm{mg})$ were treated with a solution of acetyl bromide $(\mathrm{AcBr})$ in acetic acid $(20 \%, \mathrm{v} / \mathrm{v})$ at $50{ }^{\circ} \mathrm{C}$ for $2.5 \mathrm{~h}$ in a $3 \mathrm{dram}$ vial with a vacuum-sealed cap. The acetylated and benzyl-brominated lignin solution was dried under vacuum for $40 \mathrm{~min}$ at $50{ }^{\circ} \mathrm{C}$. The dry film was treated with absolute ethanol $(1 \mathrm{~mL})$, which was then also removed on a SpeedVac concentrator at $50{ }^{\circ} \mathrm{C}$ for $15 \mathrm{~min}$. The dry sample was then immediately dissolved in a mixture of 1,4-dioxane:acetic acid:water (5:4:1, by volume, $5 \mathrm{~mL}$ ), and zinc nano-powder $(150 \mathrm{mg})$ was added to the vial. The reaction was stirred for $16 \mathrm{~h}$ at room temperature and then quenched with saturated ammonium chloride. The quenched reaction was spiked with an internal standard mixture (deuterated monolignols and conjugates). The organics were extracted with DCM $(3 \times 15 \mathrm{~mL})$ and the combined organic fractions were dried over sodium sulfate. The DCM was removed under vacuum, and the free hydroxyl groups were acetylated overnight using a mixture of acetic anhydride and pyridine $(1: 1, \mathrm{v} / \mathrm{v})$. The excess acetic anhydride and pyridine were removed on a rotary evaporator, after which the crude product was loaded onto a Supelco Supelclean LC-SI SPE tube (Sigma-Aldrich) with the aid of ethyl acetate and hexane $(1: 1, \sim 1 \mathrm{~mL})$. The purified product was then eluted using a mixture of ethyl acetate:hexane (1:1, $8 \mathrm{~mL}$ ), and concentrated to dryness. The dry film was dissolved in DCM $(1 \mathrm{~mL})$ and injected into a Shimadzu GCMS-TQ8030 triple-quadrupole GC/MS/MS operating in multiple-reaction-monitoring (MRM) mode for quantitative analysis (using calibration curves derived from synthetic standards). Each line represents an average of five biological replicates composed of two technical replicates each for greenhouse-grown lines, and an average of two pools of ten plants for field-grown lines. The error bars represent the standard deviation between the biological replicates. Statistical analysis was performed by paired $t$ tests between $c c r 1$ mutants and corresponding wild-type plants with a significance level of 0.05 .

\section{Digestibility analysis}

Digestibility analysis to yield glucose and pentoses was performed as described in [22], using $\sim 2 \mathrm{mg}$, accurately weighed, of mature rind tissue sample for each of three technical replicates. Each line represents an average of five biological replicates for greenhouse-grown lines, and an average of two pools of ten plants for field-grown lines. Statistical analysis was performed by paired $t$ tests between $c c r 1$ mutants and corresponding wild-type plants with a significance level of 0.05 . 


\section{Additional file}

Additional file 1. Figure 1. Molecular characterization of the mu1013391 insertion in Zmccr1. A) Scale diagram of the ZmCCR1 locus GRMZM2G131205, Chr1: 211567137..211573211. Black and white boxes represent exons and untranslated regions, respectively, while lines indicate introns. Shown is the location of the Uniform Mu insertion mu1013391 (triangle) in seed lots UFMu00732 (Zmccr 1a) and UFMu01379 (Zmccr 1b) along with relative primer locations (arrows). B) Shown are agarose gel-electrophoresed PCR products indicating either the presence (primers T1 + R1, $375 \mathrm{bp}$ ) or absence (primers F1 + R1, 537 bp) of the mu1013391 insertion in either plants homozygous for the mu1013391 insertion (Zmccr 1a and 1b) or wild-type W22. (C) Agarose gel-electrophoresed PCR products semi-quantitatively amplified from reverse-transcribed first-strand CDNA from plants either homozygous for the mu1013391 insertion (Zmccr 1a and 16) or WT B73 (primers F2 + R2, $\sim 408 \mathrm{bp}$ ). Note that the Zmccr $1 a$ and 16 PCR products appear larger than that of WT B73 due to a 12-bp insertion. GAPDH was used as a loading control (224 bp). NT = no template. Figure 2. Raw DFRC data. A) GC-MS chromatograms of coniferyl dihydro-ferulate (G-DHFA) conjugates from wild-type and ccrl Maize plants, and the Arabidopsis ccrl mutant, irx4; the highlighted region the position of the trans isomer. The asterisks indicate the sinapyl dihydro-p-coumarate peaks (cis and trans) in the maize samples that also have this MRM transition, but elute at different retention times. B) The GC-MS chromatograms of sinapyl dihydro-ferulate (S-DHFA) conjugates from Maize and Arabidopsis samples. The first highlighted peak is cis-S-DHFA and the second is trans-S-DHFA. Note that the peaks shown are from the molecular ion minus ketene $\left(\mathrm{CH}_{2}=\mathrm{C}=\mathrm{O}\right)$; this can come from the acetate on either end of the conjugate (as shown by the dotted bond).

\section{Abbreviations}

FMT: FERULOYL-COA MONOLIGNOL TRANSFERASE; CoA: coenzyme A; CCR: CINNAMOYL-COA REDUCTASE; CCr: CCR-suppressed mutant; PMT: $p$-COUMAROYL-COA MONOLIGNOL TRANSFERASE; $p$ CAT: $p$-COUMAROYLCOA ACYLTRANSFERASE; ML: monolignol; FA: ferulate; $p C A$ : $p$-coumarate; H: 4-hydroxyphenyl; G: 3-methoxy-4-hydroxyphenyl; S: 3,5-dimethoxy4-hydroxyphenyl; ML-FA: monolignol ferulate conjugate; ML-pCA: monolignol $p$-coumarate conjugate; $\mathrm{NaOH}$ : sodium hydroxide; $\mathrm{Zm}$ : Zea mays; WT: wild type; RNA: ribonucleic acid; RNAi: ribonucleic acid interference; cDNA: complementary deoxyribonucleic acid; PCR: polymerase chain reaction; RT: reverse transcriptase; sqPCR: semi-quantitative polymerase chain reaction; MMLV: Murine leukemia virus; GAPDH: glyceraldehyde 3-phosphate dehydrogenase; bp: base pair; v/v: volume to volume; h: hour; min: minute; GC: gas chromatography; MS: mass spectrometry; MRM: multiple reaction monitoring; RF: response factor; AcBr: acetyl bromide; DCM: dichloromethane; AIR: alcohol insoluble residue; DFRC: derivatization followed by reductive cleavage; AFEX: ammonia fiber expansion; DOE: United States of America Department of Energy.

\section{Authors' contributions}

RAS, CC, SDK, MM, HK, SDM, NdL, SMK, JS, and JR designed the project. RSS, $\mathrm{MH}, \mathrm{NdL}, \mathrm{SMK}$, and MM grew the plants and determined the biometric data. RAS, CC, and SDK processed the samples and analyzed the data. RAS, CC, SDK, MM, SMK, JS, and JR wrote the manuscript. All authors discussed the results and commented on the draft.

\section{Author details}

1 Department of Energy Great Lakes Bioenergy Research Center, The Wisconsin Energy Institute, University of Wisconsin-Madison, 1552 University Avenue, Madison, WI 53726-4084, USA. ${ }^{2}$ Department of Biochemistry, University of Wisconsin-Madison, Madison, WI 53706, USA. ${ }^{3}$ Department of Energy Great Lakes Bioenergy Research Center, School of Biological Sciences, Illinois State University, Normal, IL 61790, USA. ${ }^{4}$ Department of Agronomy, University of Wisconsin-Madison, Madison, WI 53706, USA. ${ }^{5}$ Department of Wood Science, University of British Columbia, Vancouver, BC, Canada. ${ }^{6}$ Present Address: Department of Genetics and Biochemistry, Clemson University, Clemson, USA.

\section{Acknowledgements}

The authors would like to thank Michigan State University's Cell Wall Facility, particularly Cliff Foster, Shane Cantu, and Nick Santoro, for performing the thioacidolysis and digestibility analyses.

\section{Competing interests}

The authors declare that they have no competing interests.

\section{Availability of supporting data}

Data sharing is not applicable to this article as no datasets were generated or analyzed during the current study.

\section{Funding}

This research was funded by the DOE Great Lakes Bioenergy Research Center (DOE Office of Science BER DE-FC02-07ER64494).

\section{Publisher's Note}

Springer Nature remains neutral with regard to jurisdictional claims in published maps and institutional affiliations.

Received: 8 February 2017 Accepted: 18 April 2017

Published online: 02 May 2017

\section{References}

1. Wilkerson CG, Mansfield SD, Lu F, Withers S, Park J-Y, Karlen SD, GonzalesVigil E, Padmakshan D, Unda F, Rencoret J, et al. Monolignol ferulate transferase introduces chemically labile linkages into the lignin backbone. Science. 2014;344(6179):90-3.

2. Miksche GE. Lignin reactions in alkaline pulping processes (rate processes in soda pulping). In: Nakano J, Singh RP, editors. Chemistry of delignification with oxygen, ozone, and peroxides. Tokyo: Uni Publishers Co.; 1980. p. 107-20.

3. Karlen SD, Zhang C, Peck ML, Smith RA, Padmakshan D, Helmich KE, Free HCA, Lee S, Smith BG, Lu F, et al. Monolignol ferulate conjugates are naturally incorporated into plant lignins. Sci Adv. 2016;2(10):e1600393.

4. Grabber JH, Hatfield RD, Lu F, Ralph J. Coniferyl ferulate incorporation into lignin enhances the alkaline delignification and enzymatic degradation of maize cell walls. Biomacromol. 2008;9(9):2510-6.

5. Derikvand MM, Sierra JB, Ruel K, Pollet B, Do CT, Thevenin J, Buffard D, Jouanin L, Lapierre C. Redirection of the phenylpropanoid pathway to feruloyl malate in Arabidopsis mutants deficient for cinnamoyl-CoA reductase 1. Planta. 2008;227(5):943-56.

6. Ralph J, Kim H, Lu F, Grabber JH, Leplé J-C, Berrio-Sierra J, Mir Derikvand M, Jouanin L, Boerjan W, Lapierre C. Identification of the structure and origin of a thioacidolysis marker compound for ferulic acid incorporation into angiosperm lignins (and an indicator for cinnamoyl-CoA reductase deficiency). Plant J. 2008;53(2):368-79.

7. Leplé J-C, Dauwe R, Morreel K, Storme V, Lapierre C, Pollet B, Naumann A, Kang K-Y, Kim H, Ruel K, et al. Downregulation of cinnamoyl-coenzyme A reductase in poplar: multiple-level phenotyping reveals effects on cell wall polymer metabolism and structure. Plant Cell. 2007;19(11):3669-91.

8. McCarty DR, Settles AM, Suzuki M, Tan BC, Latshaw S, Porch T, Robin K, Baier J, Avigne W, Lai J, et al. Steady-state transposon mutagenesis in inbred maize. Plant J. 2005;44(1):52-61.

9. Jones $L$, Ennos AR, Turner SR. Cloning and characterization of irregular xylem4 (irx4): a severely lignin-deficient mutant of Arabidopsis. Plant Journal. 2001:26(2):205-16.

10. Tamasloukht B, Lam MSJWQ, Martinez Y, Tozo K, Barbier O, Jourda C, Jauneau A, Borderies G, Balzergue S, Renou JP, et al. Characterization of a cinnamoylCoA reductase 1 (CCR1) mutant in maize: effects on lignification, fibre development, and global gene expression. J Exp Bot. 2011;62(11):3837-48.

11. Park SH, Mei CS, Pauly M, Ong RG, Dale BE, Sabzikar R, Fotoh H, Nguyen T, Sticklen M. Downregulation of maize cinnamoyl-coenzyme A reductase via RNA interference technology causes brown midrib and improves ammonia fiber expansion-pretreated conversion into fermentable sugars for biofuels. Crop Sci. 2012;52(6):2687-701. 
12. Marita JM, Hatfield RD, Rancour DM, Frost KE. Identification and suppression of the $p$-coumaroyl CoA:hydroxycinnamyl alcohol transferase in Zea mays L. Plant J. 2014;78(5):850-64.

13. Petrik DL, Karlen SD, Cass CL, Padmakshan D, Lu F, Liu S, Le Bris P, Antelme S, Santoro N, Wilkerson CG, et al. p-Coumaroyl-CoA: monolignol transferase (PMT) acts specifically in the lignin biosynthetic pathway in Brachypodium distachyon. Plant J. 2014;77(5):713-26.

14. Withers S, Lu F, Kim H, Zhu Y, Ralph J, Wilkerson CG. Identification of a grass-specific enzyme that acylates monolignols with $p$-coumarate. J Biol Chem. 2012;287(11):8347-55.

15. Cullis IF, Saddler JN, Mansfield SD. Effect of initial moisture content and chip size on the bioconversion efficiency of softwood lignocellulosics. Biotechnol Bioeng. 2004;85(4):413-21.

16. Robinson AR, Mansfield SD. Rapid analysis of poplar lignin monomer composition by a streamlined thioacidolysis procedure and near-infrared reflectance-based prediction modeling. Plant Journal. 2009;58(4):706-14.

17. Lapierre C. Determining lignin structure by chemical degradations. In: Heitner C, Dimmel DR, Schmidt JA, editors. Lignin and lignans: advances in chemistry. New York: CRC Press, Taylor \& Francis Group; 2010. p. 11-48.
18. Lu F, Ralph J. The DFRC method for lignin analysis. Part 2. Monomers from isolated lignins. J Agric Food Chem. 1998;46(2):547-52.

19. Lu F, Ralph J. The DFRC method for lignin analysis. Part 3. NMR studies. J Wood Chem Technol. 1998;18(2):219-33.

20. Lu F, Ralph J. The DFRC method for lignin analysis. Part 1. A new method for $\beta$-aryl ether cleavage: lignin model studies. J Agric Food Chem. 1997:45(12):4655-60.

21. Lu F, Ralph J. Detection and determination of $p$-coumaroylated units in lignins. J Agric Food Chem. 1999;47(5):1988-92.

22. Santoro N, Cantu SL, Tornqvist CE, Falbel TG, Bolivar JL, Patterson SE, Pauly M, Walton JD. A high-throughput platform for screening milligram quantities of plant biomass for lignocellulose digestibility. Bioenerg Res. 2010;3(1):93-102.

\section{Submit your next manuscript to BioMed Central and we will help you at every step:}

- We accept pre-submission inquiries

- Our selector tool helps you to find the most relevant journal

- We provide round the clock customer support

- Convenient online submission

- Thorough peer review

- Inclusion in PubMed and all major indexing services

- Maximum visibility for your research

Submit your manuscript at www.biomedcentral com/submit 